\title{
Efeito do tratamento térmico e adição do Lactobacillus acidophilus no processamento do queijo tipo brie
}

Effect heat treatment and addition Lactobacillus acidophilus on the processing brie cheese

Efecto del tratamiento térmico y la adición de Lactobacillus acidophilus en el procesamiento del queso brie

\section{Resumo}

O queijo tipo brie é um produto com boa aceitação no Brasil, a estimativa é que esta classe de queijo represente cerca de $3 \%$ da produção mundial de queijos. O presente trabalho teve como objetivo desenvolver queijos tipo brie com leite cru e pasteurizado adicionados de cultura probiótica, constituída de Lactobacillus acidophilus, cultura inicial Lactococcus lactis, cultura secundária Penicillium candidum, bem como avaliar o efeito do tratamento térmico e da adição da cultura probiótica nas características físico-químicas e perfil eletroforético após trinta dias de maturação, a $10{ }^{\circ} \mathrm{C}$. Os queijos tipo brie foram processados em batelada, sendo processados cinco formulações. Foram realizadas caracterizações físico-químicas e perfil eletroforético bem como a viabilidade da cultura probiótica do L. acidophilus após a maturação. As amostras com tratamento térmico apresentaram características diferentes das obtidas com leite cru, refletindo na composição físico-química dos queijos. A mobilidade eletroforética relativa, posição das bandas protéicas, e seus respectivos pesos moleculares em maior abundância nos queijos foram identificadas como: $\alpha \mathrm{S}_{1^{-}}$ caseína $(23,61 \mathrm{kDa}), \alpha \mathrm{S}_{2}$-caseína $(25,23 \mathrm{kDa}), \beta$-caseína $(23,98 \mathrm{kDa})$, к-caseína $(19,02 \mathrm{kDa})$ e $\alpha$ - lactoalbumina (14,2 $\mathrm{kDa}$ ). Em todos os queijos obtidos o microrganismo Lactobacillus acidophilus apresentaram viabilidade do microrganismo acima do mínimo recomendado, na ordem de $10^{7} \mathrm{UFC} / \mathrm{g}$. O que mostra que o queijo tipo brie é uma boa matriz para o probiótico analisado.

Palavras-chave: Queijos com mofo branco; Probiótico; Leite cru; Leite pasteurizado.

\section{Abstract}

Brie cheese is a product with good acceptance in Brazil, the estimate is that this class of cheese represents about $3 \%$ of the world cheese production. This work aimed to develop brie cheeses with raw and pasteurized milk added with probiotic culture, consisting of Lactobacillus acidophilus, initial culture Lactococcus lactis, secondary culture Penicillium candidum, as well as to evaluate the effect of heat treatment and the addition of probiotic culture in 
physical-chemical characteristics and electrophoretic profile after thirty days of maturation, at $10^{\circ} \mathrm{C}$. Brie cheeses were processed in batches, with five formulations being processed. Physical-chemical characterizations and electrophoretic profile were carried out, as well as the viability of the probiotic culture of L. acidophilus after maturation. The samples with heat treatment showed different characteristics from those obtained with raw milk, reflecting in the physical-chemical composition of the cheeses. The relative electrophoretic mobility, position of the protein bands, and their respective molecular weights in greater abundance in the cheeses were identified as: $\alpha$ S1casein $(23.61 \mathrm{kDa}), \alpha$ S2-casein $(25.23 \mathrm{kDa}), \beta$-casein $(23.98 \mathrm{kDa})$, к-casein $(19.02 \mathrm{kDa})$ and $\alpha$-lactalbumin $(14.2$ $\mathrm{kDa}$ ). In all cheeses obtained, the microorganism Lactobacillus acidophilus showed viability of the microorganism above the recommended minimum, in the order of $10^{7} \mathrm{CFU} / \mathrm{g}$. Which shows that brie cheese is a good matrix for the probiotic analyzed.

Keywords: Cheese with white mold; Probiotic; Raw milk; Pasteurized milk.

\section{Resumen}

El queso brie es un producto con buena aceptación en Brasil, la estimación es que esta clase de queso representa alrededor del $3 \%$ de la producción mundial de queso. Este trabajo tuvo como objetivo desarrollar quesos brie con leche cruda y pasteurizada adicionada con cultivo probiótico, consistente en Lactobacillus acidophilus, cultivo inicial Lactococcus lactis, cultivo secundario Penicillium candidum, así como evaluar el efecto del tratamiento térmico y la adición de cultivo probiótico en características físico-químicas y perfil electroforético a los treinta días de maduración, a $10{ }^{\circ} \mathrm{C}$. Los quesos brie se procesaron en lotes y se procesaron cinco formulaciones. Se realizaron caracterizaciones físico-químicas y perfil electroforético, así como la viabilidad del cultivo probiótico de $L$. acidophilus después de la maduración. Las muestras con tratamiento térmico presentaron características diferentes a las obtenidas con leche cruda, reflejándose en la composición físico-química de los quesos. La movilidad electroforética relativa, la posición de las bandas proteicas y sus respectivos pesos moleculares en mayor abundancia en los quesos se identificaron como: $\alpha$ S1-caseína (23,61 kDa), $\alpha$ S2-caseína (25,23 kDa), $\beta$-caseína (23,98 kDa), кcaseína $(19,02 \mathrm{kDa})$ y $\alpha$-lactoalbúmina $(14,2 \mathrm{kDa})$. En todos los quesos obtenidos, el microorganismo Lactobacillus acidophilus mostró viabilidad del microorganismo por encima del mínimo recomendado, del orden de $10^{7} \mathrm{UFC} / \mathrm{g}$. Lo que demuestra que el queso brie es una buena matriz para el probiótico analizado.

Palabras clave: Queso con moho blanco; Probiótico; Leche cruda; Leche pasteurizada.

\section{Introdução}

No Brasil, segundo os dados divulgados pela Associação Brasileira das Indústrias de Queijos (Abiq), em 2019 o país produziu 1,2 milhões de toneladas de queijo, ficando entre os cinco maiores produtores do mundo. O estado de Minas Gerais é o maior produtor do país, com cerca de $25 \%$ da produção nacional. O consumo brasileiro é de cerca de 5,5 kg de queijo por habitante no ano, valor ainda considerado baixo quando comparado a países como Grécia (20 kg) e Argentina (11 kg), no entanto, a produção e consumo de queijos finos e artesanais tem aumentado no país ilustrando a importância social e econômica dos queijos (Soares \& Rodrigues, 2019).

O queijo tipo brie é um produto com boa aceitação e sua produção no Brasil ocorre com o mesmo protocolo utilizado para o queijo tipo Camembert, sendo diferenciado apenas por seu tamanho. O queijo tipo brie nacional, possui em média 20 cm de diâmetro, matura num único corpo e é fracionado após completar o ciclo de maturação. Este queijo caracteriza-se por sua massa macia e quebradiça e é maturado por bactérias láticas e pelo fungo Penicillum candidum, fungo que confere sabor característico ao queijo, além de formar uma casca branca aveludada ao redor do mesmo. A estimativa é que esta classe de queijo represente cerca de 3\% da produção mundial de queijos (Pereira, 2014; Spinnler, 2017; Pereira et al., 2020).

A qualidade de um produto está associada a qualidade das matérias primas empregadas no seu desenvolvimento. Do mesmo modo, para que a qualidade do queijo em relação aos aspectos físico-químicos e microbiológicos seja garantida é necessário assegurar que o leite empregado no processamento esteja dentro aos padrões necessários para tal aplicação. Assim, o tratamento térmico a que é submetido o leite destinado a fabricação de queijos é essencial na qualidade final do produto, já que pode promover mudanças nos seus vários constituintes, principalmente nas diferentes frações protéicas. Para minimizar estas mudanças, tem-se selecionado cepas que façam parte da microbiota presente no leite cru, de modo a obter culturas iniciadoras e adjuntas especificamente preparadas para adição ao leite tratado termicamente e destinado à produção de queijos (Menegon, 2019). 
Segundo Albenzio et al. (2001), no queijo obtido com leite cru observa-se uma microbiota natural com atividade metabólica que possibilita o desenvolvimento de um perfil sensorial distinto. As diferenças observadas vão desde as características sensoriais e bioquímicas, além de $\mathrm{pH}$ superior em queijos obtidos com leite cru. O processo produtivo de queijos maturados tende a favorecer o desenvolvimento da microbiota lática presente naturalmente no leite, que por sua vez atua inibindo o crescimento de espécies nocivas por meio da produção de ácidos orgânicos e outros metabólitos inibitórios. Deste modo, após determinada etapa do processo de maturação, os queijos tornam-se seguros ao consumo, sendo estes tipos de queijos cada vez mais procurados e consumidos pela população (Pereira, 2014; Pehrson, 2017).

A palavra 'probióticos' tem origem na palavra grega 'para a vida'. De acordo com as diretrizes da FAO / OMS, os probióticos são definidos como organismos vivos que conferem benefícios à saúde do hospedeiro quando administrados em quantidades adequadas. Os probióticos também são definidos como bactérias vivas que contribuem para a regulação das respostas imunológicas e têm efeitos benéficos no hospedeiro. Resistência a patógenos entéricos, auxílio na digestão da lactose, efeito anticâncer do cólon, crescimento bacteriano do intestino delgado e modulação do sistema imunológico são algumas das ações benéficas das bactérias probióticas. Certos critérios precisam ser atendidos por uma bactéria para se qualificar como um probiótico: ela deve ser inofensiva para ingestão, capaz de colonizar o epitélio intestinal e, especialmente, ser capaz de resistir às condições adversas encontradas no trato gastrointestinal (Lima et al., 2020).

O desenvolvimento de produtos lácteos contendo bactérias probióticas específicas com concentrações apropriadas de células viáveis durante a vida de prateleira é um desafio tecnológico. Culturas probióticas têm sido incorporadas com sucesso em diferentes tipos de queijos, pois representam um forte nicho entre os alimentos funcionais além de ser uma alternativa para as indústrias de laticínios diversificarem seus produtos em um mercado consumidor cada vez mais competitivo (Stanton, 2001; Kourkoutas et al., 2005; Hill et al., 2014; Govender et al., 2014; Dantas et al., 2016).

Diante do exposto o presente trabalho tem como objeto desenvolver queijos tipo brie com leite cru e pasteurizado adicionados de cultura probiótica, constituída de Lactobacillus acidophilus, bem como avaliar o efeito do tratamento térmico e da adição da cultura probiótica nas características físico-químicas e perfil eletroforético após trinta dias de maturação.

\section{Metodologia}

\subsection{Material}

O leite bovino utilizado na pesquisa foi fornecido por uma pequena propriedade localizada no município de Bananeiras - PB. Os queijos tipo brie foram obtidos com leite cru e leite pasteurizado para posterior comparação dos resultados das suas características. As culturas de bactérias láticas utilizadas foram adquiridas mediante compra, sendo adicionadas ao leite de acordo com as instruções dos fabricantes por inoculação direta. A cultura comercial liofilizada de Lactobacillus acidophilus LYO 10 foi fornecida pela Howaru Premium Probiotics, enquanto a cultura comercial de Lactococcus lactis MA 11 LYO e esporos do fungo Penicillium candidum PC $12 \mathrm{LYO}$, foram fornecidas pela Choozit Danisco. Foram mantidas sob congelamento a $-18{ }^{\circ} \mathrm{C}$ até o momento de uso. A enzima quimosina utilizada para coagulação do leite foi adquirida mediante compra, sendo fornecida de forma líquida pela HA-LA, diluída e adicionada ao leite por inoculação direta de acordo com instruções do fabricante. Para a adição de cálcio foi utilizado uma solução aquosa com cloreto de cálcio na dosagem de $50 \%$ (50 mL de solução para cada $100 \mathrm{~L}$ de leite).

\subsection{Caracterização físico-química do leite}

As caracterizações foram determinadas seguindo às metodologias do Instituto Adolfo Lutz (IAL, 2005), do seguinte modo: acidez titulável foi determinada pelo método de titulação com hidróxido de sódio 0,1 N (solução Dornic), empregando- 
se o indicador fenolftaleína a $1 \%$. A densidade a $15{ }^{\circ} \mathrm{C}$ foi determinada utilizando termolactodensímetro. $\mathrm{O}$ teor de gordura ( $/$ /100 g) das amostras de leite foi determinado pelo método butirométrico de Gueber. Em proteínas, o nitrogênio total foi determinado pelo método de Kjeldahl e o resultado total convertido em porcentagem de proteína $(\% \mathrm{~m} / \mathrm{m})$ foi obtido multiplicando pelo fator 6,38 . O extrato seco total $(\% \mathrm{~m} / \mathrm{m})$ foi determinado com o auxílio do disco calculador de Ackermann, levando em consideração o teor de gordura e densidade a $15{ }^{\circ} \mathrm{C}$. O extrato seco desengordurado foi obtido por cálculo de diferença. O potencial hidrogeniônico foi determinado eletrometricamente com a utilização de um potenciômetro.

\subsection{Procedimento experimental e análise estatística}

Os queijos tipo brie foram processados em batelada, sendo processados cinco formulações. As formulações foram codificadas do seguinte modo:

QLCSP: Queijo com leite bovino cru, contendo a cultura mesófila iniciadora composta de Lactococcus lactis e cultura secundária composta de Penicillium candidum e sem adição de probiótico.

QLCCP: Queijo com leite bovino cru, contendo a cultura mesófila iniciadora composta de L. lactis, cultura secundária composta de $P$. candidum e cultura lática de Lactobacillus acidophilus.

QLPSP*: Queijo com leite bovino pasteurizado, contendo a cultura iniciadora composta de L. lactis, cultura secundária composta de $P$. candidum e sem adição de probiótico.

QLPSP**: Queijo com leite bovino pasteurizado, contendo cultura iniciadora composta de L. lactis, cultura secundária composta de $P$. candidum, sem adição de cloreto de cálcio e probiótico.

QLPCP: Queijo com leite bovino pasteurizado, contendo cultura iniciadora composta de L. lactis, cultura secundária composta de $P$. candidum e cultura lática de L. acidophilus.

Quatro tratamentos foram adicionados de solução de cloreto de cálcio (50\%), para averiguar a ação do cloreto de cálcio em relação a rendimento e melhoramento de características físico-químicas, um tratamento foi realizado sem a adição da solução de cloreto de cálcio para posterior comparação. Para caracterização os queijos foram maturados a $10{ }^{\circ} \mathrm{C} \pm 2{ }^{\circ} \mathrm{C}$ durante trinta dias. As análises dos queijos obtidos foram realizadas em triplicatas.

Foram realizadas estatísticas descritivas simples com média, desvio padrão e coeficiente de variância com os dados obtidos em todas as caracterizações obtidas.

\subsection{Processamento do queijo tipo brie}

Para produção dos queijos, foi utilizado o protocolo de produção proposto por Ribeiro (2012), com adaptações. A amostra foi dividida em duas, sendo uma alíquota mantida in natura e outra submetida a tratamento térmico de pasteurização rápida, $75{ }^{\circ} \mathrm{C}$ por 15 segundos, após aquecimento o leite foi resfriado a $34{ }^{\circ} \mathrm{C}$ em banho de gelo. Em seguida, o processamento foi o mesmo das amostras obtidas com leite in natura.

Inicialmente, para cada 8,2 litros de leite processado, foi adicionado o fermento lático composto de Lactococcus lactis ( $0,18 \mathrm{~g})$, Penicillium candidum ( $0,5 \mathrm{~g})$ e a cultura probiótica Lactobacillus acidophilus $(1 \mathrm{~g})$ em dois tratamentos. Foi adicionado também $3 \mathrm{~mL}$ de uma solução de cloreto de cálcio (50\%) e 45 minutos depois, o coalho, permitindo a coagulação por aproximadamente 45 minutos. Após a formação da coalhada a mesma foi cortada com liras em cubos, com tamanho entre 1,5 a 2,0 cm de aresta, permanecendo em repouso por aproximadamente 20 minutos.

A mexedura foi realizada de forma lenta, por 5 minutos, para dessora do cubo. A massa foi então enformada em formas de PVC, com fundo perfurado de $500 \mathrm{~g}$, não sendo realizada a prensagem, a moldagem se deu com o peso da própria 
massa. A prensagem influencia na textura e sinérese dos queijos e como o queijo tipo brie possui textura macia, os queijos não foram submetidos à prensagem.

As viragens foram realizadas em diferentes momentos: 30 e 45 minutos após a enformagem, 60 minutos após a primeira viragem, 30 minutos após a terceira viragem, 60 minutos após a quarta viragem e 30 minutos após a quinta viragem, para auxiliar na dessora e no formato do queijo.

A fase da formatação ocorreu em aproximadamente quinze horas a $25^{\circ} \mathrm{C}$. Os queijos foram então desenformados e salgados em salmoura com $20 \%$ de sal por 50 minutos. A salmoura foi preparada um dia antes e mantida sob refrigeração, pois a temperatura ideal para salga dos queijos é de 8 a $12^{\circ} \mathrm{C}$.

Em seguida, passaram por um processo de secagem, onde os queijos foram dispostos em bandejas plásticas e mantidos em B.O.D por uma hora com temperatura a $10{ }^{\circ} \mathrm{C}$. Logo após a secagem, os queijos foram submetidos a aplicação por aspersão de uma solução de esporos do Penicillium candidum $(0,006 \mathrm{~g}$ de esporos $+100 \mathrm{~mL}$ de água destilada) em todas as suas faces. Após isso foi realizada a maturação por 30 dias a $10^{\circ} \mathrm{C}$. O ideal seria um controle de umidade relativa na câmara de maturação em torno de $90 \%$.

\subsection{Caracterização físico-química dos queijos tipo brie}

As caracterizações foram realizadas do seguinte modo: o teor de gordura $(\mathrm{g} / 100 \mathrm{~g})$ das amostras de queijo foi determinado pelo método butirométrico de Van Gulik. Em proteínas o conteúdo de nitrogênio total dos queijos foi determinado empregando-se o método de micro Kjedahl, compreendendo as fases de digestão, destilação e titulação, os resultados foram expressos em (g/100 g). Atividade de água foi determinada através de método instrumental em medidor da marca Decagon, modelo Aqualab lite, à temperatura constante $\left(25,0 \pm 0,30^{\circ} \mathrm{C}\right)$. O potencial hidrogeniônico foi determinado com a utilização de um potenciômetro. $\mathrm{O}$ teor de cinzas foi determinado em mufla a $550{ }^{\circ} \mathrm{C}$ e os resultados expressos em (g/100 g). A acidez titulável foi determinada pelo método de titulação com hidróxido de sódio $0,1 \mathrm{~mol} / \mathrm{L}$, empregando-se o indicador fenolftaleína a $1 \%$ e os resultados expressos em \% de ácido lático. A umidade foi determinada em estufa a $105{ }^{\circ} \mathrm{C}$ e os resultados expressos em $(\mathrm{g} / 100 \mathrm{~g})$. O teor de gordura no extrato seco foi determinado pelo método indireto por meio da razão entre o teor de umidade e gordura, conforme equação: $\% \mathrm{GES}=(\%$ gordura $) \div($ umidade -100$)$ x $100 . \mathrm{O}$ teor de extrato seco desengordurado foi determinado pelo método indireto por meio da diferença entre GES e teor de gordura (Brasil, 2006). Os resultados foram tratados utilizando estatística descritiva simples.

\subsection{Perfil eletroforético}

$\mathrm{Na}$ eletroforese dos queijos obtidos o método utilizado foi o de eletroforese em gel de poliacrilamida com SDS modificado (Laemmli, 1970).

A solução estoque de SDS (dudecil sulfato de sódio foi preparado com $5 \mathrm{~g}$ de SDS e $50 \mathrm{~mL}$ de água desmineralizada). Para seguir com nitrato de prata, utilizou-se o gel corado com comassie; a solução foi desidratada em solução de álcool etílico a $50 \%$ em três etapas de 20 minutos cada. O gel foi colocado em solução de tiossulfato de sódio $(20 \mathrm{mg} / 100 \mathrm{~mL}$ de água desmineralizada) por 1 minuto sob agitação vai e vem no recipiente. Realizou-se três lavagens rápidas com água destilada, adição da solução de nitrato de prata (200 mg de nitrato de prata, $74 \mu 1$ de formaldeído/ $100 \mathrm{~mL}$ de água desmineralizada) por 20 minutos. Foram realizadas três lavagens rápidas com água destilada e adição de solução reveladora $(6 \mathrm{~g}$ de carbonato de sódio, $50 \mu 1$ de formaldeído, $2 \mathrm{~mL}$ tiossulfato de sódio/100 $\mathrm{mL}$ de água desmineralizada). A revelação foi parada com solução de ácido acético a 13\% em água após 15 minutos.

Quanto menor a concentração de acrilamida mais aberto é o poro do gel e consequentemente, melhor é a separação para proteínas de maior peso molecular. Dentre os géis testes, o gel de separação foi preparado na concentração 7,5\%. Para a 
corrida eletroforética, a fonte elétrica foi regulada para a tensão de corrida no gel de concentração $(80 \mathrm{~V})$, a corrente para 25 $\mathrm{mA}$, iniciando a corrida. Quando a linha azul formada pelo marcador da corrida (azul de bromofenol) ultrapassou a linha do gel de concentração (cerca de 2 horas depois), o gel foi mantido em solução fixadora por uma hora e transferido para um recipiente contendo solução corante. Permaneceu imerso, cerca de 12 a 14 horas (overnight), sendo então transferidos para outro recipiente contendo solução descorante, onde foi mantida por cerca de 2 horas até atingir a coloração adequada. Foram obtidas imagens dos géis, com os dados de mobilidade eletroforética relativa e massa molecular de cada fração protéica detectada através da formação das bandas.

\subsection{Avaliação da viabilidade da cultura probiótica Lactobacillus acidophilus}

A viabilidade da cultura probiótica adicionada aos queijos foi avaliada com base na contagem seletiva de Lactobacillus acidophilus. Para a realização dessa análise, amostras de queijo foram diluídas em água peptonada. Porções de $25 \mathrm{~g}$ de queijo foram transferidas para um copo de liquidificador, previamente esterilizado, juntamente com $225 \mathrm{ml}$ de água peptonada $0,1 \%$, para serem homogeneizadas em baixa rotação, por 1-2 min. A partir dessa suspensão (diluição $10^{-1}$ ) foram preparadas as demais diluições decimais das amostras, utilizando a mesma solução diluente.

A contagem presuntiva de L. acidophilus foi realizada de acordo com a metodologia descrita por Aljewicz et al. (2014), modificada somente por substituição da incubação anaeróbica pela incubação em microaerofilia (Apha, 2001). A contagem foi realizada em ágar MRS, utilizando a técnica de semeadura em profundidade. Ainda, foi adicionada uma sobrecamada do mesmo meio de cultura, para criar condições microaerofílicas. Após solidificação do meio de cultura, as placas foram invertidas e incubadas em estufa a $37{ }^{\circ} \mathrm{C}$ por 72 horas. Após incubação, placas com 25-250 colônias foram contadas, utilizando um contador de colônias, e os resultados foram expressos em UFC/g.

\section{Resultados e Discussão}

\subsection{Caracterização físico-química do leite bovino}

O valor nutricional dos alimentos é definido com base na sua composição centesimal. A composição média da matéria prima implica, na qualidade do produto final. Vários fatores influenciam na composição e qualidade do leite, as mudanças ligadas ao manejo e a dieta oferecida ao animal, o que reflete na qualidade do queijo. Os resultados das análises físicoquímicas do leite cru e leite pasteurizado estão apresentados na Tabela 1.

Os padrões físico-químicos das análises realizadas nas amostras de leite cru e leite pasteurizado foram comparadas com os previstos pela Instrução Normativa $\mathrm{n}^{\circ} 62$ de dezembro de 2011 do Ministério da Agricultura Pecuária e Abastecimento (Brasil, 2011). 
Tabela 1. Parâmetros físico-químicos das amostras de leite cru e leite pasteurizado.

\section{Parâmetros}

Gordura $\%(\mathrm{~m} / \mathrm{m})$

Proteínas $\%(\mathrm{~m} / \mathrm{m})$

Densidade $(\mathrm{g} / \mathrm{mL})$

$$
\mathrm{pH}^{* *}
$$

\section{Leite Cru}

$$
\begin{gathered}
3,45 \pm 0,21 \\
3,42 \pm 0,04 \\
1,028 \pm 0,001 \\
6,55 \pm 0,01
\end{gathered}
$$

$0,132 \pm 0,001$

$12,36 \pm 0,10$

$8,91 \pm 0,10$

\section{Leite Pasteurizado}

$$
\begin{gathered}
4,35 \pm 0,07 \\
3,88 \pm 0,63 \\
1,030 \pm 0,002 \\
6,65 \pm 0,07
\end{gathered}
$$

$0,145 \pm 0,000$

$11,84 \pm 0,79$

$7,49 \pm 0,79$

Extrato seco desengordurado \% $(\mathrm{m} / \mathrm{m})$

Os resultados são médias em triplicatas com as estimativas do desvio padrão. ** Potencial hidrogeniônico.

Fonte: Autoras.

Com relação aos teores de gordura, tanto às amostras de leite cru $(3,45 \mathrm{~g} / 100 \mathrm{~g})$ quanto de leite pasteurizado $(4,35$ g/100g), estão em acordo com a IN 62, que é de no mínimo (3,0 g/100g). A gordura do leite é de extrema importância para a produção de derivados e possui alto valor comercial, portanto, a determinação exata do percentual de gordura no leite é essencial para a indústria de laticínios (Castanheira, 2011).

Já em relação às proteínas, todas as amostras apresentaram conteúdo protéico acima do mínimo (2,9\%) exigido pela legislação. No entanto, houve variação em relação ao conteúdo de proteínas no leite cru (3,42\%) e no leite pasteurizado $(3,88 \%)$, isto pode ter ocorrido devido a evaporação de água e consequente concentração dos outros constituintes. O teor de proteína aumenta o rendimento na fabricação de queijos.

A densidade corresponde ao peso específico do leite, que é determinado por dois grupos de substâncias: a concentração de elementos em solução e suspensão e porcentagem de gordura. Se o leite sofre adição de água de forma fraudulenta, apresentará um valor mais baixo para sua densidade. Os teores de densidade obtidos para leite cru e leite pasteurizado estão de acordo $(1,028 \mathrm{~g} / \mathrm{mL}$ e $1,030 \mathrm{~g} / \mathrm{mL}$ respectivamente) com o que preconiza a legislação (entre 1,028 e 1,034 $\mathrm{g} / \mathrm{mL})$.

As amostras de leite cru analisadas apresentaram valor um pouco abaixo $(0,132 \mathrm{~g}$ de ácido lático/100 $\mathrm{mL}$ de leite) dos padrões estabelecidos para acidez $(0,14$ - 0,18 g de ácido lático/100 mL de leite). Já as amostras de leite pasteurizado apresentaram valor de acordo com a legislação $(0,145 \mathrm{~g}$ de ácido lático/100 mL de leite). A acidez titulável reflete a produção de ácido lático, sendo indicador de higiene e conservação do leite, teores elevados remetem a falta de higiene ou transporte inadequado, principalmente em relação a temperatura, o que ocasiona a proliferação de bactérias e a consequente produção de ácido lático (Rheinheimer, 2006).

A medida que a acidez aumenta, ocorre abaixamento do $\mathrm{pH}$. Na IN 62 os parâmetros que indicam qualidade sanitária e estabilidade térmica variam de $(6,4$ a 6,9$)$, portanto, os valores obtidos de $(6,55$ e 6,65$)$ estão em conformidade com o que preconiza a legislação.

O extrato seco total é a reunião dos componentes sólidos do leite e é importante para o rendimento de derivados do leite, quanto maior a quantidade de sólidos totais, melhor o rendimento deste leite para a produção de queijos. O extrato seco desengordurado reflete o mesmo comportamento (Santos et al., 2011). A legislação remete a valores de no mínimo (8,4 g/100g) para este parâmetro, estando as amostras de leite cru e leite pasteurizado dentro dos padrões tanto para extrato seco total quanto para extrato seco desengordurado. 
As amostras analisadas apresentaram-se em conformidade as normas da Instrução Normativa $n^{\circ}$ 62. Esses resultados comprovam a qualidade do leite em estudo, evidenciando características sanitárias adequadas para o seu potencial uso na obtenção de queijos tipo brie.

\subsection{Caracterização físico-química dos queijos tipo brie}

A composição físico-química dos queijos tipo brie, determinada após trinta dias de maturação é apresentada na Tabela 2.

Tabela 2. Composição físico-química dos queijos obtidos com leite cru e pasteurizado.

\begin{tabular}{|c|c|c|c|c|c|}
\hline Parâmetros & QLCCP & QLCSP & QLPSP* & QLPSP** & QLPCP \\
\hline Gordura \% (m/m) & 52,0 & 53,0 & 43,0 & 52,0 & 49,0 \\
\hline Umidade $\%(\mathrm{~m} / \mathrm{m})$ & $28,71 \pm 0,17$ & $24,37 \pm 0,06$ & $24,86 \pm 0,08$ & $35,47 \pm 0,15$ & $25,10 \pm 0,11$ \\
\hline Atividade de água & $0,84 \pm 0,001$ & $0,84 \pm 0,001$ & $0,85 \pm 0,002$ & $0,84 \pm 0,001$ & $0,853 \pm 0,001$ \\
\hline $\begin{array}{c}\text { Acidez titulável (\% de } \\
\text { ácido lático) }\end{array}$ & 0,26 & 0,28 & 0,28 & 0,23 & 0,28 \\
\hline Proteínas \% $(\mathrm{m} / \mathrm{m})$ & $27,66 \pm 0,04$ & $29,15 \pm 0,22$ & $29,25 \pm 0,30$ & $25,84 \pm 0,13$ & $28,41 \pm 0,06$ \\
\hline $\mathbf{p H} * * *$ & 5,30 & 5,08 & 5,22 & 5,02 & 5,0 \\
\hline $\begin{array}{c}\text { Gordura no Extrato Seco } \\
\qquad \%(\mathbf{m} / \mathbf{m})\end{array}$ & $71,88 \pm 0,17$ & $70,07 \pm 0,06$ & $57,22 \pm 0,08$ & $80,58 \pm 0,15$ & $65,33 \pm 0,11$ \\
\hline $\begin{array}{c}\text { Extrato seco } \\
\text { desengordurado \% }(\mathrm{m} / \mathrm{m})\end{array}$ & $19,88 \pm 0,16$ & $17,07 \pm 0,06$ & $14,22 \pm 0,08$ & $28,58 \pm 0,15$ & $16,33 \pm 0,11$ \\
\hline Cinzas $\%(\mathrm{~m} / \mathbf{m})$ & $4,79 \pm 0,03$ & $3,86 \pm 0,08$ & $4,19 \pm 0,02$ & $4,68 \pm 0,02$ & $3,36 \pm 0,08$ \\
\hline
\end{tabular}

QLCCP: Queijo com leite cru e probiótico. QLCSP: Queijo com leite cru sem probiótico. QLPSP*: Queijo com leite pasteurizado sem probiótico com cloreto de cálcio. QLPSP**: Queijo com leite pasteurizado sem probiótico sem cloreto de cálcio. Queijo com leite pasteurizado com probiótico. Os resultados são médias em triplicatas com as estimativas do desvio padrão. *** Potencial hidrogeniônico. Fonte: Autoras.

A legislação brasileira não apresenta padrão de identidade e qualidade específico para o queijo tipo brie, o qual deve respeitar os parâmetros básicos do Regulamento Técnico de Identidade e Qualidade estabelecido pelo Ministério da Agricultura Pecuária e Abastecimento, Portaria n ${ }^{\text {146/1996. }}$

A amplitude para umidade de queijos de massa macia de acordo com a IN 146/96 é de 46\% a 54,9\%. Todos os tratamentos no presente estudo ficaram abaixo dos padrões, variando de $24,37 \mathrm{~g} / 100 \mathrm{~g}$ a $35,47 \mathrm{~g} / 100 \mathrm{~g}$, isto se deve a desidratação dos queijos ao longo da maturação. Galli (2018) em estudos com queijos tipo camembert com adição de Lb. rhamnosus, obteve resultados de umidade que variaram de 47,74 g/100g a 50,57 g/100g. Pereira (2014), ao avaliar queijos tipo brie industriais em diferentes períodos do ano também constatou umidade abaixo do ideal, com teores que variaram de (39,64 $\mathrm{g} / 100 \mathrm{~g}$ a $45,05 \mathrm{~g} / 100 \mathrm{~g})$.

A variação de umidade possui relação com o processamento e maturação, principalmente quando a maturação é realizada em câmaras com controle de temperatura e umidade. Neste período o queijo deve permanecer com umidade ambiente acima de $90 \%$, para favorecer o desenvolvimento do micélio e manter as características de textura no produto. Se ocorrer algum problema, ou falta de controle o queijo pode perder umidade e apresentar teores mais baixos (Furtado, 2008; Pereira et al., 2020).

Em relação à gordura, a Portaria $n^{\circ}$ 146/96 do MAPA considera o conteúdo de matéria gorda no extrato seco. O queijo tipo brie enquadra-se como gordo, devendo apresentar entre 45,0 a 59,99\% de gordura. Em todos os tratamentos os queijos estão dentro do que estabelece a legislação, enquanto o teor de gordura no extrato seco apresentou teores muito altos, o que 
possui relação com a umidade. Pois, o mesmo foi calculado a partir da umidade e gordura do produto. Os valores variaram bastante e uma observação interessante é que a única amostra ao qual não foi adicionada solução de cloreto de cálcio, nem $L$. acidophilus apresentou o maior índice de gordura no extrato seco e maior índice de extrato seco desengordurado. Pode-se observar que o tratamento térmico também apresentou influência nestes parâmetros, os queijos obtidos sem tratamento térmico tiveram maior conteúdo de gordura que os obtidos com leite pasteurizado, exceto para amostra sem cloreto de cálcio.

A gordura no extrato seco é um dos principais constituintes responsáveis pela obtenção de um bom rendimento final do queijo. Campos (2016) obteve em seus tratamentos com queijos camembert valores de gordura variando de $(17,12 \% \mathrm{~m} / \mathrm{m}$ a $17,19 \% \mathrm{~m} / \mathrm{m})$ e Gordura no Extrato Seco variando de (36,57\% a 39,25\%).

Para os teores de cinzas, a recomendação da USDA Nutrient Database for Standard Reference, Release 14 (2001) e de teores de $(2,7 \mathrm{~g} / 100 \mathrm{~g})$, porém nenhum dos tratamentos obtidos nesta pesquisa está dentro desta referência variando de $(3,36$ $\mathrm{g} / 100 \mathrm{~g} \mathrm{a} 4,79 \mathrm{~g} / 100 \mathrm{~g}$ ). A alimentação do rebanho quando possui uma dieta rica em concentrados com baixo teor de fibras pode elevar os teores minerais do leite e, consequentemente do queijo (Pereira, 2014).

Ao analisar queijos tipo brie industriais obtidos em diferentes estações do ano, Pereira et al. (2020) constatou diferenças nos teores de cinzas (3,07 g/100g, 3,74g/100g, 4,90 g/100g). Campos (2016), em pesquisa com queijos camembert sem mexedura e com adição de compostos protéicos, obteve resultados de cinza que variaram entre $(2,97 \mathrm{~g} / 100 \mathrm{~g}$ e 2,87 $\mathrm{g} / 100 \mathrm{~g})$.

Os teores de acidez variaram de 0,234 a 0,281\% de ácido lático. A acidez tende a aumentar de acordo com o crescimento dos microrganismos, no transcorrer do período do armazenamento, beneficiando o produto por inibir a microbiota patogênica. No entanto, a acidez excessiva pode prejudicar os aspectos sensoriais em queijos, descaracterizando o produto (Sangaletti, 2007). Freitas Filho et al., (2009), obtiveram resultados de acidez em sua pesquisa com queijo coalho artesanal com variação de 0,113 a $0,495 \%$ de ácido lático.

A determinação do potencial hidrogeniônico é importante para caracterização de queijos devido a sua influência na textura, atividade microbiana e na maturação. O menor valor de $\mathrm{pH}$ obtido $(5,0)$ foi o da amostra com tratamento térmico e adição da cepa probiótica, possivelmente ocorreu uma maior produção de ácido lático. O que pode ser verificado no teor de acidez dessa amostra $(0,281 \%$ de ácido lático).

A atividade de água dos queijos apresentou valores distintos, apresentando variação entre 0,841 a 0,853 , sendo o tratamento de menor valor o que também apresentou menor teor de umidade. Henão, Queiroz e Hajisa (2009) descrevem este parâmetro como a medida de água disponível em um alimento, não vinculada a componentes, tornando-se possível de reagir quimicamente e permitir o desenvolvimento microbiano. A atividade de água ideal para o desenvolvimento de bactérias lácteas varia de 0,93 a 0,96 dependendo da espécie (Beresford et al., 2001).

A legislação brasileira não descreve valores legais para proteínas em queijos. Os valores obtidos variaram de (25,84 a $29,25 \mathrm{~g} / 100 \mathrm{~g}$ ), sendo os queijos com adição de solução de cloreto de cálcio os que apresentaram maiores teores de proteínas. Amostras de queijo que sofreram tratamento térmico apresentaram resultados para proteínas dentro da média não apresentando influência significativa quando comparados com os queijos obtidos com leite cru, exceto a formulação sem adição de cloreto de cálcio, que apresentou o menor teor protéico. Pereira (2014), observou em seus tratamentos com queijo tipo brie valores entre $(18,59$ a 21,57 g/100g). Pesquisadores citam que o coalho e o cloreto de cálcio influenciam na quantidade de proteína presente em queijos, pois exercem interferências na proteólise durante a maturação (Yunes \& Benedet, 2000).

\subsection{Análise do perfil eletroforético}

As frações protéicas dos cinco queijos brie obtidos, analisados por eletroforese, estão ilustradas na Figura 1. As frações de caseínas encontradas e seus respectivos pesos moleculares em maior abundância nos queijos foram identificadas 
como: $\alpha \mathrm{S}_{1}$-caseína $(23,61 \mathrm{kDa}), \alpha \mathrm{S}_{2}$-caseína $(25,23 \mathrm{kDa}), \beta$-caseína $(23,98 \mathrm{kDa})$, к-caseína $(19,02$ kDa) e $\alpha$ - lactoalbumina $(14,2 \mathrm{kDa})$.

Pode-se observar na Figura 1, diferenças distintas das amostras de queijos obtidos com leite pasteurizado e com leite cru. As amostras de queijo com leite cru apresentaram bandas com coloração mais intensa e mais concentrada. Tal fato pode ser resultado da interação das proteínas induzidas termicamente ou dos próprios microrganismos presentes nas culturas láticas. As proteínas do queijo ficaram muito bem dispostas e separadas nos géis, confirmando a eficácia da técnica para esta função. Fragmentos de $\alpha \mathrm{S}_{1}, \alpha \mathrm{S}_{2, \beta}$-caseína e к-caseína são referidas na literatura como as principais proteínas do queijo, originadas da hidrólise da caseína pela ação da quimosina, enzima coagulante, utilizada durante a fabricação do queijo (Jin et al., 2016).

Figura 1. Perfil eletroforético das amostras de queijos obtidas.

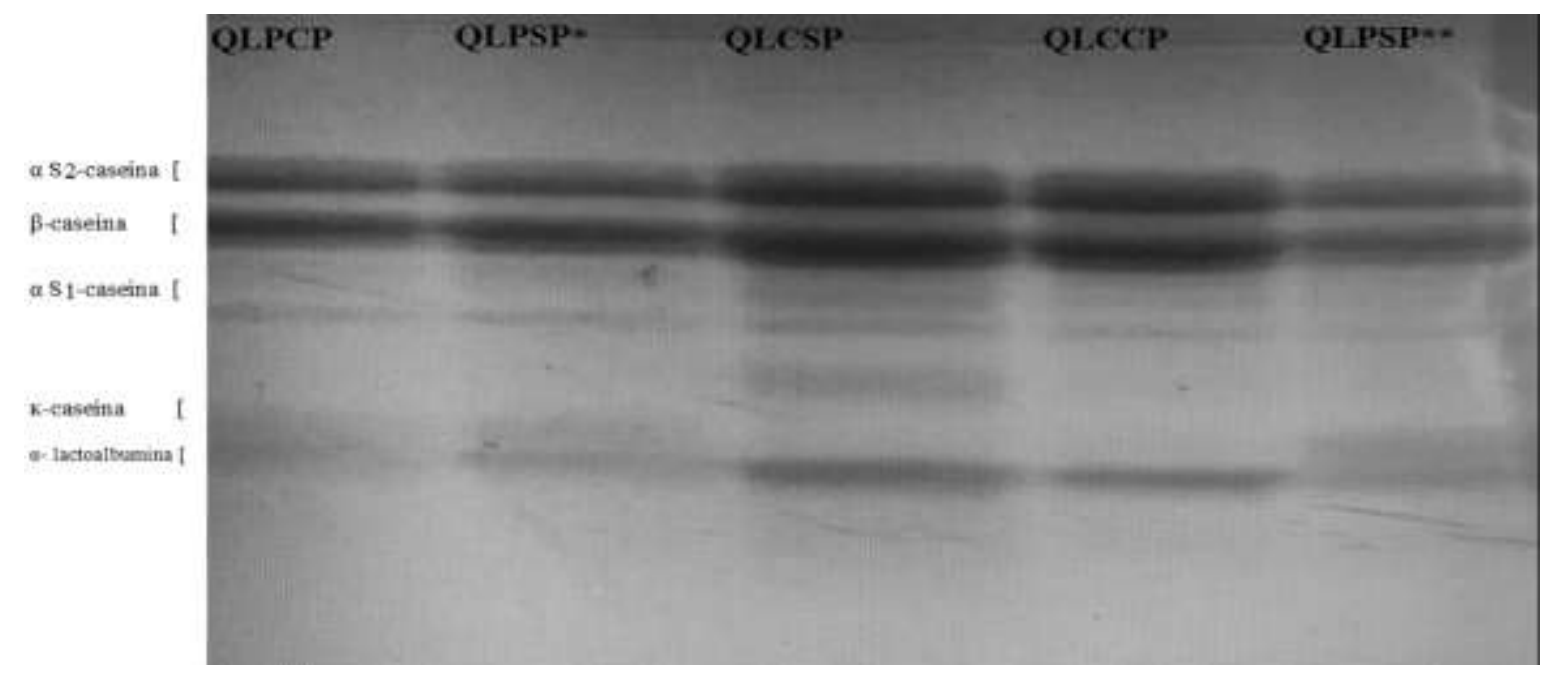

QLPCP: Queijo leite pasteurizado com probiótico. QLPSP*: Queijo leite pasteurizado sem probiótico. QLCSP: Queijo leite cru sem probiótico. QLCCP: Queijo leite cru com probiótico. QLPSP**: Queijo leite pasteurizado sem probiótico e sem cloreto de cálcio.

Fonte: Autoras.

As bandas referentes aos fragmentos de $\alpha \mathrm{S}_{1}, \alpha \mathrm{S}_{2, \beta}$-caseína e $\alpha$-lactoalbumina foram mais intensificadas com os queijos obtidos sem tratamento térmico (QLCSP e QLCCP), bandas referentes ao fragmento K-caseína foram mais intensificadas com queijos obtidos com tratamento térmico (QLPCP, QLPSP* e QLPSP**). Ao comparar as amostras que tiveram a adição do probiótico com e sem tratamento térmico, observa-se que a adição do probiótico aumentou a intensidade das frações protéicas evidenciando que o probiótico L. acidophilus influenciou positivamente no perfil protéico dos queijos obtidos.

Comparando as amostras de queijo produzido com leite pasteurizado sem probiótico com cloreto de cálcio (QLPSP*) da amostra sem cloreto de cálcio (QLPSP**), pode-se observar que a amostra com a adição de cloreto de cálcio apresentaram bandas protéicas mais unidas e intensas. A amostra (QLPSP**) apresentou menor intensidade em todas as frações protéicas, podendo deste modo afirmar que a adição do cloreto de cálcio exerce boa influência no perfil protéico do queijo.

Silva et al., (2016) ao analisarem eletroforeticamente queijo coalho produzidos em diferentes cidades da região agreste do estado de Pernambuco relatam a presença de bandas que correspondiam a $\beta$-lactoglobulina, $\alpha$-lactoalbumina, $\alpha \mathrm{S}_{1}, \alpha$ $\mathrm{S}_{2}$, $\beta$-caseína. O mesmo pode ser observado por Lima et al., (2017) que, ao investigar os peptídeos extraídos de queijo coalho artesanal, identificaram as mesmas frações protéicas identificadas neste estudo e concluíram que as mesmas apresentavam atividades antimicrobianas. 
Como características destas frações protéicas, a $\alpha$-lactoalbumina é bastante rica em triptofano (6\%), um aminoácido precursor de niacina, sendo também rica em lisina, leucina, treonina e cistina, além de possuir capacidade de se ligar a minerais, como cálcio e zinco, o que pode afetar positivamente sua absorção. Apresenta ainda atividade antimicrobiana contra bactérias patogênicas como Escherichia coli, Staphylococcus aureus e Klebsiella pneumonial (Aditivos e ingredientes, 2016). De acordo com Pereira et al., (2016) as frações $\alpha S_{1}, \alpha S_{2}, \beta$-caseína e a $\kappa$-caseína possuem propriedades funcionais características, apresentam sensibilidade a precipitação de cálcio, melhor coagulabilidade do leite, melhoram o rendimento e apresentam atividade antimicrobiana.

\subsection{Contagem presuntiva de Lactobacillus acidophilus}

Os resultados das contagens de Lactobacillus acidophilus em ágar MRS a partir de amostras de queijo tipo brie obtidas a partir de leite cru e pasteurizado, ambas adicionados dessa cultura probiótica foram os seguintes: 4,9 x10 $0^{7} \mathrm{UFC} / \mathrm{g}$ (QLCCP) e 9,2 x 107 UFC/g (QLPCP). Esses resultados demonstraram que os lactobacilos estavam presentes nas amostras de queijos em números elevados, na ordem de $10^{7} \mathrm{UFC} / \mathrm{g}$.

Segundo a ISO 20128:2006 os produtos com alegação funcional devem ter bactérias Lactobacillus acidophilus com populações de, no mínimo, $10^{4}$ unidades formadoras de colônia por grama (UFC/g) de queijo e no mínimo $10^{6}$ unidades formadoras de colônia por grama (UFC/g) para outras bactérias. As duas formulações adicionadas de Lactobacillus acidophilus estão com contagem acima da preconizada pela legislação em vigor, evidenciando que mesmo após 30 dias de maturação as características do probiótico mantiveram-se estáveis, apresentando deste modo bom desempenho tecnológico.

Avaliando o comportamento do L. acidophilus no ágar MRS, observaram-se contagens entre (4,9 x $\left.10^{7} \mathrm{UFC} / \mathrm{g}\right)$ para o queijo obtido com leite cru e o obtido com leite pasteurizado (9,2 x $\left.10^{7} \mathrm{UFC} / \mathrm{g}\right)$. Uma menor contagem deste microrganismo no queijo obtido com leite cru era esperada, pois existem atividades inibitórias e competitivas entre microrganismos presentes na microbiota natural do leite e o Lactobacillus acidophilus. Buriti e Saad (2007) avaliaram a sobrevivência de L. acidophilus em queijo minas frescal produzido com acidificação direta com ácido lático e também com adição de cultura mesófila Lactococcus lactis. No tipo de queijo avaliado, a cultura probiótica permaneceu viável durante 21 dias de armazenamento, no entanto, no queijo contendo a cultura mesófila, as contagens de L. acidophilus foram ligeiramente superiores, sugerindo um sinergismo entre os microrganismos. No queijo contendo apenas L. acidophilus, a concentração atingiu valores abaixo de $10^{6} \mathrm{UFC} / \mathrm{g}$.

\section{Considerações Finais}

O leite utilizado apresentou características físico-químicas de acordo com o estabelecido pela Instrução Normativa no 62 de 29/12/2011 do Ministério da Agricultura Pecuária e Abastecimento, apresentando teor de gordura e de proteína maior que o estabelecido, sendo estas características importantes para qualidade e rendimento do queijo.

O baixo teor de umidade apresentado pelos queijos tipo brie após trinta dias de maturação afetou a qualidade bioquímica e a textura dos queijos obtidos.

Os queijos obtidos com leite sem tratamento térmico apresentaram melhor rendimento e características físicoquímicas satisfatórias, no entanto, pela segurança do consumidor o recomendado seria a obtenção de queijos com o leite com tratamento térmico.

Todos os ensaios de queijo tipo brie produzidos com adição da cultura probiótica de Lactobacillus acidophilus apresentaram viabilidade do microrganismo acima do mínimo recomendado, os lactobacilos estavam presentes nas amostras de queijos obtidos com leite cru e leite pasteurizado em números elevados, na ordem de $10^{7} \mathrm{UFC} / \mathrm{g}$. O que mostra que o queijo tipo brie é uma boa matriz para o probiótico analisado. 
Como sugestão para trabalhos futuros, seria interessante a implantação de um sistema de Boas práticas de fabricação do leite cru, de modo a se obter produtos seguros e em relação à maturação dos queijos, recomenda-se embalar os queijos no $10^{\circ}$ dia de maturação para evitar interferências na textura e na qualidade bioquímica do produto.

\section{Referências}

Aditivos e ingredientes. (2016). As proteínas lácteas e a saúde. Proteínas lácteas. Revista Aditivos e ingredientes. Editora Insumos Ltda, 20-26.

Albenzio, M., Corbo, M. R., Rehman, S. U., Fox, P. F., Angelis, M. D., Corsetti, A., Sevi, A., \& Gobetti, M. (2001). Microbiological and biochemical caracteristics of canestrato Pugliese cheese made from raw milk, pasteurized milk or by heating the curd in hot whey. International Journal of food Microbiology, 67(1), $35-48$.

Aljewicz, M., Cichosz, G., Nalepa, B., \& Kowalska, M. (2014). Influence of the probiotic Lactobacillus acidophilus NCFM and Lactobacillus rhamnosus HN001 on proteolysis patterns of Edam cheese. Food Technol. Biotechnol. 52 (4) 439-447.

American Public Health Association - APHA (2001). Compendium of methods for the microbiological examination of foods. (4a ed.), Washington.

Beresford, P. T., Fitzsimons, A. N., Brennan, L. N., \& Cogan, M. T. (2001). Recent advances in cheese microbiology. Internacional Dairy Journal. 11, 259 274.

Brasil. Ministério da Agricultura, Pecuária e Abastecimento. (2006). Instrução Normativa n ${ }^{\circ}$ 68, de 12 de dezembro de 2006 . Oficializa os métodos analíticos oficiais físico-químicos para controle de leite e produtos lácteos. Diário Oficial da União, Brasília, DF, 14 dez.

Buriti, F. C. A., \& Saad, S. M. I. (2007). Bactérias do grupo Lactobacillus casei: caracterização, viabilidade como probióticos em alimentos e sua importância para a saúde humana. Arch. Latinoamericanos de Nutricion. 57(4), 373- 380, 2007.

Campos, S. A. S. (2016). Caracterização sensorial e microscópica de queijo tipo camembert elaborado sem mexedura e com adição de concentrados lácteos protéicos. Dissertação- UFLA, Lavras.

Castanheira, A. C. G. (2011). Manual básico de controle de qualidade de leite e derivados: cap.

Dantas, A. B., Jesus, V. F., Silva, R., Almada, C. N., Esmerino, E. A., \& Cappato, L. P. (2016). Manufacture of probiotic Minas frescal cheese with Lactobacillus casei Zhang. Journal of Dairy Science, 99(1), 18-30.

Freitas Filho, J. R., Souza Filho, J. S., Oliveira, H. B., Angelo, J. H. B., \& Bezerra, J. D. C. (2009). Avaliação da qualidade do queijo "coalho" artesanal fabricado em Jucati-PE. Extensio - Revista Eletrônica de extensão.6(8), 35-49.

Furtado, M. M. (2008). Caracterização histórica. Tecnologia de fabricação, características físico químicas, sensoriais, perfil de textura e de comercialização do queijo reino. Dissertação - Universidade Federal de Lavras.

Galli, B. D. (2018). Perfil de peptídeos de queijo tipo camembert: efeito do tratamento térmico e do uso de cultura adjunta Lactobacillus rhamnosus GG. Dissertação mestrado- Universidade Estadual de Campinas, FEA - Campinas, SP, 136p.

Govender, Y., Avenant, C., Verhoog, N. J., Ray, R. M., Grantham, N. J., Africander, D., \& Hapgood, J. P. (2014). The injectable only contraceptive Medroxyprogesterone acetate, unlike Norethisterone acetate and Progesterone, Regulates Inflammatory genes in endocervical cells via the glucocorticoid receptor.

Henão, J. D., Queiroz, M. R., \& Hajisa, N. M. A. (2009). Umidade de equilíbrio de café cereja descascado baseadas em métodos estático e dinâmico. Revista Brasileira de Engenharia Agrícola e Ambiental, 13(4), 470-476.

Hill, C., Guarner, F., Reid, G., Gibson, G. R., Merenstein, D. J., Pot, B., Morelli, L., Canani, R. B., Flint, H. J., Salminen, S., Calder, P. C., \& Sanders, M. E. (2014). Expert consensus document: The International Scientific Association for Probiotics and Prebiotics consensus statement on the scope and appropriate use of the term probiotic. Nature Reviews gastroenterology e hepatology, 11, 506 - 514.

Instituto Adolf Lutz. (2005). Métodos físico-químicos para análise de alimentos. (4a ed.).

ISO 20128: 2006. Milk products - Enumeration of presumptive Lactobacillus acidophilus on a selective medium - colony-count technique at $37^{\circ} \mathrm{C}$. IDF 192 : 2006.

Jin, Y., YU, Y., Qi, Y., Wang, F., Yan, J., \& Zou, H. (2016). Peptide profiling and the bioactivity character or yogurt in the simulated gastrointestinal digestion. Journal of Proteomics, Valencia, 141, 24-46.

Kourkoutas, Y., Xolias V., Kallis M., Bezirtzoglou, E., \& Kanellaki, M. (2005). Lactobacillus casei cell immobilization on fruit pieces for probiotic additive, fermented milk and lactic acid production. Process Biochem., 40(1), 411- 416.

Laemmli, U. K. Cleavage of structural proteins during the assembly of the head of bacteriophage T4. Nature, 227, 680 -685, 1970.

Lima, C. P., Dias, G. M. P., Soares, M. T. C. V., Bruno, L. M., \& Porto, A. L. F. (2020). Coalho cheese as source of probiotic lactic acid bacteria. Research, Society and Development, 9(8), e266984958, (CC BY 4.0)| ISSN 2525-3409 | DOI: http://dx.doi.org/10.33448/rsd-v9i8.4958.

Lima, M. S. F., Silva, R. A., Filho, J. L. L., Porto, A. L. F., \& Cavalcanti, M. T. H. (2017). Queijo de Coalho artesanal: fonte alternativa de peptídeos antimicrobianos. Brazilian Journal of Food Technology, Campinas, 20(0), 1-7. 
Menegon, T. (2019). Avaliação dos parâmetros de qualidade de queijo mussarela obtido a partir de leite armazenado e leite fresco. Trabalho de Conclusão de Curso, Universidade Tecnológica Federal do Paraná, Medianeira.

Ministério da Agricultura, do abastecimento e da reforma agrária. (2011). Instrução Normativa ${ }^{\circ}$ 62. Regulamento técnico de produção de identidade e qualidade de leite crurefrigerado, regulamento técnico de identidade e qualidade de leite pasteurizado e regulamento técnico da coleta de leite cru refrigerado e seu transporte a granel. Diário oficial da união, 29 de dezembro.

Pehrson, M. E. S. F. (2017). Efeito da adição de culturas probióticas sobre aspectos microbiológicos e parâmetros fermentativos de queijo artesanal das terras altas da Mantiqueira. Tese de doutorado em Ciências - Programa de Pós Graduação em Biotecnologia Industrial na área de Microbiologia Aplicada. Escola de Engenharia de Lorena da Universidade de São Paulo, Lorena - SP.

Pereira, A. C. P. (2014). Características físicas, químicas e microbiológicas de queijos tipo brie e tipo camembert produzidos no Brasil. Dissertação Mestrado em Ciência e Tecnologia de Alimentos, Universidade Estadual de Ponta Grossa. Ponta Grossa.

Pereira, A. C. P., Judacewski, P., Coelho, G., Salem, R. D. S., Marinho, M. T., Alberti, A., Zielinski, A. A. F., Demiate, I. M., \& Nogueira. A. (2020). Assessment os physochemical, textural and microbiological properties of brazilian white mold surface- ripened cheeses: a technological approach. Ciência Rural, 50:1, e20190595, Santa Maria.

Pereira, M. J., Lima, C. S., Bueno, C. P., Neves, B. S., \& Coelho, K. O. (2016). O rendimento de queijo muçarela em função do teor de caseína acima de 80\%. IV Congresso de Ensino, Pesquisa e Extensão da UEG. Universidade Estadual de Goiás, Goiás.

PLOS One, 9 (5) e96497.

Rheinheimer, V. V., Dürr, J. W., Hepp, M. A. W., Moro, D. V., Jacobs, M. R. C., Antoni, V. L., Saggioratto, M. A., Dal'maso, G. A., Rodrigues, L. B., Soares, J., Doro, C., Benedetti, S., \& Fontaneli, R. S. (2006). Qualidade do leite fluído de diferentes marcas comercializadas em Passo Fundo. In: Congresso Brasileiro de Qualidade do Leite, 2. Anais. Goiânia.

Sangaletti, N. (2007). Estudo da vida útil do queijo Minas frescal disponível no mercado. 81f. Dissertação (Mestrado em Ciência e Tecnologia de Alimentos). Universidade de São Paulo Escola Superior de Agricultura "Luiz de Queiroz", Piracicaba.

Santos, N. A. F., Ribeiro, A. C., Lima, M. F.V., Galvão, N. R., Vieira, M. M., Silva, M. I. S., \& Tenório, T. G. S. (2011). Avaliação da composição e qualidade físico química do leite pasteurizado e comercializado na cidade de São Luís, MA. Arg. Inst. Bio, São Paulo, 78(1), 109-113.

Silva, R. A., Bezerra, V. S., Pimentel, M do. C., Portal, A. L., Cavalcanti, M. T., \& Filho, J. L. (2016). Proteomic and peptidomic profiling of Brazilian artisanal 'Coalho' cheese. Journal of the Science of Food and Agriculture, EUA, 96(13), 4337-4344.

Soares, L., \& Rodrigues, F. (2019). bghv "Com 25\% da população nacional, MG aposta no queijo como saída para crise e geração de renda". <https://g1.globo.com/mg/sul-de-minas/minas-dos-queijos/noticia/2019/05/20/com-25percent-da-producao-nacional-mg-aposta-no-queijo-como-saida-paracrise-e-geracao-de-renda.ghtml $>$.

Spinnler, H. -E. Surface mold-ripened cheeses. In: Mcsweeney, P. L. H., Fox, P. F., Paul, D., Cotter, P. D., \& Everett, D.W. (Eds). (2017). Cheese: chemistry, physics and microbiology, (4th ed.), pp.911-928: Academic Press.

Stanton, C. Market potential for probiotics. (2001). The American Journal of Clinical Nutrition,Houston, USA, 73(3), 476-483.

Yunes, V. M., \& Benedet, H. D. (2000). Desenvolvimento experimental de queijo fresco de leite da espécie bubalina. Ciência Tecnologia alimentar, 20(3). 